\title{
A CONCILIAÇÃO ENTRE A FORMAÇÃO ESPORTIVA E A ESCOLAR: UMA JOGADA PERFEITA
}

\author{
THE CONCILIATION BETWEEN SPORTS AND SCHOOL FORMATION: A PERFECT \\ MOVE
}

\author{
(iD) Hergos Ritor Froes de Couto \\ Doutor em Educação pela Universidade Nove de Julho. \\ Professor Associado da Universidade Federal do Oeste do Pará - UFOPA. Santarém. \\ hergos@hotmail.com
}

\begin{abstract}
Resumo: No Brasil e no mundo, muitos meninos e meninas desejam tornar-se jogadores de futebol profissional. Todavia, o percurso para a realização deste intento é permeado por renúncias e sacrifícios. Em muitos casos, esses jovens se dedicam quase que exclusivamente à formação esportiva e, nesse processo, boa parte acaba descuidando da formação escolar. Entretanto, é de conhecimento público que poucos jogadores chegarão à categoria profissional e menos ainda os que conseguirão independência financeira e ascensão social. O objeto deste estudo caracterizou-se por entender como, atualmente, os jovens jogadores de futebol da categoria de base Sub 17 do Futebol Clube do Porto e os pais desses esportistas operam com a situação de gerir a conciliação da formação esportiva com a escolar, sem que haja prejuízo ao desenvolvimento de alguma delas. Desenvolveu-se uma linha metodológica que se enquadrou em uma pesquisa de base qualitativa. Em relação ao instrumento de pesquisa, foram utilizadas entrevistas semiestruturadas e para análise dos dados utilizou-se a técnica do Discurso do Sujeito Coletivo (DSC). Considerou-se que as hipóteses deste estudo não se confirmaram, pois os jogadores expuseram que, apesar das dificuldades encontradas, é muito importante conciliar a formação esportiva com a escolar, demonstrando bom discernimento sobre a possibilidade de ocorrer fracasso ou sucesso na trajetória futebolística e na perspectiva de realização de outras carreiras. Já os pais valorizam a formação escolar e se mostram presentes e participativos, apoiando, acompanhando e cobrando o desempenho dos filhos na escola, com vistas à continuidade dos estudos no ensino superior.
\end{abstract}

Palavras-chave: categorias de base; formação escolar; formação esportiva; futebol.

Abstract: In Brazil and in the world, many boys and girls wish to become professional soccer players, but the path to this attempt is permeated by renunciations and sacrifices. In many cases, such young people engage almost exclusively in sports training, and in this process much of them end up neglecting school education. However it is public knowledge that few players will reach the professional category and even fewer those who will achieve financial independence and social ascension. The purpose of this study was to understand how, currently, the young football players of the base category Sub-17 of the Futebol Clube of Porto, and the parents of these athletes operate with the situation in managing the conciliation of the sports and school formation, without prejudice to the development of any of them. A methodological line was developed that was framed in a qualitative research. Regarding the research instrument, semi-structured interviews were used and the Collective Subject Discourse (DSC) technique was used to analyze the data. It was considered that the hypotheses of this study were not confirmed, since the players stated that despite the difficulties they found, it is very important to reconcile the sporting formation and schooling, and they demonstrated good discernment about the possibility of failure or success in the soccer trajectory and the perspective of achievement in other careers. Parents value school education and are present and participative in supporting, monitoring and charging the children's performance in school, with a view to continuing their studies in higher education.

Keywords: basic categories; school formation; sporting formation; soccer.

Para citar - (ABNT NBR 6023:2018)

COUTO, Hergos Ritor Froes de. A conciliação entre a formação esportiva e a escolar: uma jogada perfeita. Eccos - Revista Científica, São Paulo, n. 59, p. 1-18, e20667, out./dez. 2021. Disponível em: https://doi.org/10.5585/eccos.n59.20667. 


\section{Introdução}

Reconhecidamente, o futebol é o esporte mais popular do planeta e uma das maiores diversões de muitas pessoas em quase todos os lugares do mundo. Para se praticá-lo, precisase de uma bola, um mínimo de espaço e alguns participantes. Logo, percebe-se que tais elementos podem ser facilmente improvisados e ajustados para tal intento.

A sociedade, com frequência, estimula os primeiros impulsos que levam as crianças e os jovens a desenvolver o desejo de se tornarem jogadores de futebol. Contudo, sabe-se que também há outros fatores que influenciam este anseio, muitos dos quais são veiculados pelas diferentes mídias que projetam as imagens de sucesso de jogadores consagrados, de torcidas extasiadas, do ambiente futebolístico como alimento consubstancial da realização dessa aspiração.

Destarte, quando o pretendente vislumbra a possibilidade de realizar a construção de uma carreira futebolística, a atividade de jogar futebol, antes voltada para o lazer, toma outra proporção e se transforma em projeto de vida, em dever, alterando o enfoque de diversão e entretenimento para assumir o caráter de obrigatoriedade, incluído na esfera do trabalho. $\mathrm{O}$ futebol passa a ser, para esses aspirantes, uma maneira de ganhar a vida.

De acordo com Couto (2014), fazem-se sacrifícios pessoais e abstinências para iniciar a trajetória no mundo futebolístico, frequentemente com o envolvimento da família e de terceiros, especialmente, no aspecto financeiro, pois o sonho de sucesso, ascensão social e econômica atrai não apenas os aspirantes a jogador, mas também aqueles que estão no entorno de tais candidatos.

Entretanto, o que se percebe é que, diante desse quadro, muitos jovens atrasam-se no transcorrer das séries, ciclos, anos, ou qual seja a organização curricular. Em muitos casos, deixam de frequentar a escola, sacrificando a escolaridade à custa de muitos esforços alimentados pela aventura futebolista numa "bandeja” de possíveis ilusões.

A questão que se apresentou como objeto deste estudo relacionou-se com a preocupação de entender como, nos dias atuais, os jovens jogadores de futebol da categoria de base Sub-17 do Futebol Clube do Porto (FCPorto), grande clube português de futebol, com reconhecido sucesso no cenário europeu, e os pais destes futebolistas operam com a situação de gerir a conciliação da formação esportiva com a escolar, sem que haja prejuízo no desenvolvimento de nenhuma delas. 
É sabido que muitos jovens dedicam grande parte da juventude à busca do sucesso profissional no futebol e, nesse trajeto, muitos se descuidam da formação escolar. Contudo, a tão almejada profissionalização não ocorre para todos.

Assim, a primeira hipótese deste trabalho construiu-se na afirmação de que a formação esportiva dos jovens aspirantes a jogadores profissionais de futebol não os prepara para lidar com o fracasso, nem com o sucesso, na trajetória futebolística, mantendo-os suspensos em uma ilusão, provocando padrões de comportamento e desenvolvimento de valores sociais confusos que impedem que grande parte deles perceba possibilidades de realização em outras carreiras.

Já a segunda hipótese deste estudo partiu da premissa de que a ausência de cobrança, acompanhamento e apoio escolar por parte dos pais são fatores que podem contribuir para a desvalorização da formação escolar dos jogadores, resultando, consequentemente, em atraso nas etapas da educação básica.

Não se trata de uma temática simples, já que se lida com perspectivas de futuro de uma juventude que vislumbra, com uma imaginada trajetória de sucesso no futebol, o status social e ascensão econômica veiculada pelas diferentes mídias.

\section{$2 \mathrm{O}$ Eldorado futebolístico}

O esporte é um fenômeno sócio-cultural que produz impactos na vida das pessoas, quer sejam elas esportistas, quer não. Logo, não é demais afirmar que as manifestações esportivas realizadas ao redor do mundo e veiculadas nas diferentes mídias movimentam a sociedade que acaba consumindo ou produzindo riquezas na indústria do esporte. $O$ futebol, reconhecidamente, a modalidade esportiva mais popular do planeta, provoca expectativas de realização profissional e ascensão social e financeira, no Brasil e no mundo. Deste modo, “o futebol faz parte da identidade do País e além de ser considerado a paixão nacional, é visto como uma oportunidade de ascensão social e profissional para jovens oriundos de famílias de baixa renda" (MARQUES E SAMULSKI, 2009, p. 103).

Entretanto, é de conhecimento público que poucos jovens federados às categorias de base dos clubes formadores conseguem avançar ao futebol profissional. Segundo Brunoro e Afif (1997), ainda que um clube faça investimentos na formação de um atleta, é possível que no momento da transição para a categoria profissional, haja injustiças, pois muitos clubes não valorizam como deveriam os próprios jogadores formados nas categorias amadoras, fazendo com que a maioria não seja aproveitada na equipe principal. Com isso, muitos desses jogadores são dispensados, emprestados ou negociados com outros clubes de menor expressão. Assim, 
muitos aspirantes começam a perceber que o percurso para profissionalizar-se no futebol passa a ser uma incógnita, uma aventura com maior probabilidade de desilusões.

Há que se considerar que, no grupo seleto daqueles que alcançam a profissionalização, a quantidade dos que conseguem ter sequência na carreira diminui, assim como reduz ainda mais a parcela daqueles que obtêm realização profissional e conseguem manter uma independência financeira pós-carreira.

De acordo com Couto:

Percebe-se que as chances de se chegar ao futebol profissional são diminutas, na medida em que ocorre um verdadeiro "afunilamento" a cada obstáculo, a cada limite de categoria, até a profissionalização. O processo de ascensão às diversas categorias pode ocasionar desajustamentos emocionais e psicológicos, uma vez que a competição é muito acirrada e as reprovações são muito mais numerosas do que as aprovações, esboroando-se projetos de carreira e até mesmo de vida (2014, p. 40).

A trajetória de um jovem aspirante ao futebol profissional nas categorias de base é repleta de muitas renúncias e sacrifícios que, quase sempre, se expandem para os familiares, responsáveis e, em alguns casos, a terceiros que se vinculam a este propósito. Logo, tal empenho, aliado a esforços, transformam-se em ideais de vida.

O percurso a ser percorrido na formação do jogador de futebol passa por muitas fases. Antes de adentrar formalmente nas categorias de base de um clube, são realizados testes, também conhecidos como "peneiras", que acontecem nos clubes ou nos espaços vinculados a eles. Caso haja aprovação nas avaliações, o jogador vincula-se ao clube por meio de documentação específica da Federação Estadual à qual o clube está inscrito. A partir desse momento, o jovem candidato passa a integrar o elenco da categoria de base de acordo com sua faixa etária. A formação esportiva oferecida pelo clube passa a ocorrer sistematicamente e os jogos e competições tornam-se frequentes na vida do jogador. Vale ressaltar que as categorias amadoras dos clubes são divididas da seguinte forma: infantil - sub 15; juvenil - sub 17; júnior - sub 20.

\section{Formação esportiva}

O significado de formação, segundo o dicionário Aurélio, pode ser, entre outras coisas, "ato, efeito ou modo de formar; constituição, caráter; maneira por que se constituiu uma mentalidade, um caráter ou um conhecimento profissional" (FERREIRA, 1986, p. 800). Logo, formado pode ser entendido como alguém que adquiriu uma gama de conhecimentos relativos a determinado(s) campo(s) que o possibilita exercer alguma atividade. 
A formação é um processo humano de vir a ser:

\begin{abstract}
Mediante o qual o indivíduo natural devém um ser cultural, uma pessoa - é bom lembrar que o sentido dessa categoria envolve um complexo conjunto de dimensões que o verbo formar tenta expressar: constituir, compor, ordenar, fundar, criar, instruirse, colocar-se ao lado de, desenvolver-se, dar-se um ser. É relevante observar que seu sentido mais rico é aquele do verbo reflexivo, como que indicando que é uma ação cujo agente só pode ser o próprio sujeito (SEVERINO, 2006, p. 621).
\end{abstract}

Percebe-se que o conceito de formação é uma construção abrangente e, certamente, aplicável a diversos ambientes, entre eles o do esporte e o do espaço escolar.

No que diz respeito à formação esportiva, Lima (1988) observa que deve ser entendida como um processo pedagógico, no qual as atividades físicas e as atividades esportivas atendam, com efeito, ao meio educativo-formativo das crianças e jovens.

Segundo Pacheco (2001), formação esportiva é:

Processo globalizante, que visa não só o desenvolvimento das capacidades específicas (físicas, táctico-técnicas e psíquicas) do futebol, como também a criação de hábitos desportivos, a melhoria da saúde, bem como a aquisição de um conjunto de valores, como a responsabilidade, solidariedade e a cooperação, que contribuem para uma formação integral dos jovens (p. 39).

De fato, a formação esportiva deve ir além do desenvolvimento das habilidades inerentes a qualquer esporte. No caso deste estudo, do futebol, buscando ser um potencial atrativo para promover um processo evolutivo fundamental para a formação do indivíduo tanto enquanto jogador como também como cidadão consciente de sua função na sociedade.

Portanto, pensar na formação esportiva como um processo de fabricação de jogadores que estejam à disposição dos clubes para competir, conquistar títulos e gerar dividendos é bastante redutor. De acordo com Lima (1999), a formação esportiva deve ter um alcance social e cultural muito elevado e significativo. Assim, tal processo não pode ser ignorado pela sociedade; é fundamental estar atento a essas questões, já que o esporte, em sua real dimensão, não pode se secundarizar com interesses voltados à espetacularização, ao profissionalismo e, consequentemente, aos negócios tramados pelas indústrias do desporto.

É importante lembrar que:

... os valores que envolvem o futebol são de deixar qualquer economista perplexo: milhões de dólares ou euros. Este resultado surpreende qualquer um da economia capitalista globalizada, na qual não existe coisa melhor do que fazer com que o capital exerça seu papel, movimente-se e gere cada vez mais dinheiro para quem já tem dinheiro (MACEDO, 2006, p. 28).

Assim, a riqueza gerada no futebol, coloca-se como um elemento fortíssimo de sedução, fazendo com que os envolvidos que detêm o poder de manusear e gerir a trajetória de jovens 
jogadores ajam com ganância desmedida, aproveitando-se, muitas vezes, da ingenuidade e da fragilidade desses candidatos que almejam o futebol profissional como realização de um projeto de vida.

Sabe-se que os jogadores das categorias de base dos clubes investem fortemente na formação futebolística - neste estudo, chamada de "esportiva". Muitos deixam a família para se aventurarem no sonho do "Eldorado do Futebol", renunciando consideravelmente à vida social, diminuindo o convívio com os amigos habituais e com o sexo oposto, abdicações estas voltadas para a realização do projeto de vida que idealizam na trajetória de tornarem-se jogadores profissionais de futebol.

Segundo Damo (2005), é importante destacar que ser um jogador de futebol profissional não implica ter um nível de escolaridade alto. Todavia, requer que o jogador se dedique, aproximadamente, 5.000 horas em treinamentos para o aprendizado e aperfeiçoamento das habilidades técnicas e psicológicas específicas da prática esportiva.

\section{Formação escolar}

A doação quase que exclusiva à formação esportiva pode acarretar graves problemas no que tange à formação escolar. Este contexto deve ser foco de profundas reflexões, diálogos e discussões sérias, pois se espera que ações formativas no campo educacional devam ser revistas verdadeiramente nos e pelos clubes, no sentido de possibilitar aos jogadores uma educação que lhes forneça elementos para o desenvolvimento integral da pessoa e para a formação profissional. É importante destacar que:

\footnotetext{
A permanência na escola dos jovens atletas futebolistas vem diminuindo cada vez mais no decorrer dos anos. Muitos meninos sonham em ter um futuro brilhante no futebol e, com o mesmo, uma ascensão financeira. Contudo, após ingressarem em uma equipe de futebol, visando uma oportunidade de crescimento, muitas vezes acabam abandonando os estudos e não chegam a concluir o ensino médio (BALZANO, 2008, p. 7).
}

Segundo Brunoro e Afif (1997) não existe preocupação por parte dos clubes em adicionar elementos formativos à vida dos futuros jogadores, mesmo sabendo que muitos deles terão uma trajetória fora do futebol. Neste sentido, Damo (2005) ainda afirma que muitos jogadores abandonam a formação escolar e se dedicam inteiramente à formação no futebol; porém, para aqueles que não obtiverem êxito nesse percurso, todo o investimento será inútil.

Segundo Di Pierro (2015), no Brasil, comumente muitos jovens abandonam os estudos precocemente para se dedicarem aos esportes de competição, visando a tornarem-se atletas "de 
elite". Esse fato também ocorre em outros países ao redor do mundo, os jovens comprometemse fortemente com a formação esportiva, almejando a profissionalização no futebol, uma vez que este passa a ser o objetivo principal a ser alcançado e, por conta disso, descuidam ou abandonam o percurso escolar. Esta realidade, já constatada na trajetória de muitos jogadores espalhados pelo mundo, é um aspecto que não deve ser ignorado pela sociedade, já que muitos serão descartados no processo da formação esportiva e regressarão a seus lares com defasagens na formação escolar e, consequentemente com, menores expectativas de reconversão profissional.

Sabe-se que a escola, por suas características, pode intervir expressivamente na formação dos educandos, inclusive, com elementos fundamentais que estão presentes na formação esportiva, pois congrega condições especiais que se constituem como fatores decisivos ou complementares nesses arrolamentos. Exemplo disso são os valores e princípios desenvolvidos: espírito de equipe, recursos mentais, recursos de apreciação, raciocínio rápido, atenção, concentração, tomada de decisão, responsabilidade, disciplina, criatividade, organização, capacidade de gerir situações de estresse, memória seletiva, pensamento abstrato e outros.

\title{
5 Conciliação da formação esportiva com a escolar
}

Conciliar os espaços de tempo da formação esportiva com os da formação escolar, sem causar prejuízos no comprometimento da qualidade de ambas é, no contexto da profissionalização no futebol, o grande desafio a ser superado.

Carvalho afirma que:

\begin{abstract}
A conciliação entre as atividades desportivas e as atividades escolares dos jovens tem se revelado como um problema de difícil solução. Este problema agudiza-se sobremaneira quando pretendem enveredar por um percurso que os conduza a resultados de excelência. Uma vez que, com grande frequência existem grandes incompatibilidades entre as actividades escolares e as atividades desportivas, o sistema desportivo e o sistema educativo terão de colaborar um com o outro para que, o investimento numa delas, não obrigue a falência da outra (2002, p. 15).
\end{abstract}

Entende-se que essa conciliação não é um processo fácil na vida dos pretensos jogadores ao futebol profissional; as obrigações e os compromissos de ambas as formações ocupam muito tempo e energia. É preciso considerar também outros aspectos que estão diretamente relacionados a essa problemática, como, por exemplo, o tempo gasto nos deslocamentos para a escola, para o clube e para o local onde moram, o cansaço e as ausências causadas pelos jogos e competições. Nesse contexto complexo, a logística deve ser ponderada, pois há, aí, um 
desgaste físico, psicológico e emocional muito significativo. Entretanto, é necessário harmonizar tais atividades, permitindo que os jovens continuem seus percursos, valorizando sua formação integral.

No que diz respeito à questão do acompanhamento escolar e eventuais cobranças, é imprescindível que a família e/ou responsáveis participem, assitindo o rendimento dos filhos. Contudo, acompanhar a formação escolar deles não envolve somente cobrar. $\mathrm{O}$ acompanhamento implica também incentivar, ensinar, dialogar, prestigiar, valorizar, enfim, participar de maneira significativa, estabelecendo uma parceria séria e relevante com os jovens. Os jogadores que vivem nos alojamentos dos clubes e, consequentemente, distantes dos pais, acabam usufruindo menos dessa parceria.

Com o advento das redes sociais, a possibilidade de estabelecer contatos é facilitada; logo, é possível manter, se não fisicamente, pelo menos virtualmente, o desempenho escolar dos filhos, assistindo-os nesse processo formativo. As questões escolares devem ser de interesse de todos os agentes responsáveis pela educação dos jogadores, estabelecendo comunicações e interações frequentes para que haja o desenvolvimento esperado do educando. Portanto, fortalecer os elos deste convívio constituindo relações de confiança mútua é fundamental para gerar um ambiente de colaboração e de melhores perspectivas educacionais (PICANÇO, 2012).

Devido ao fato de o esporte apresentar uma enorme força atrativa no seio da juventude, é imprescindível que seja examinada a sua relação com a educação, buscando medidas legais que possam gerar compromissos e responsabilidades de todos os atores envolvidos na formação esportiva e escolar dos jogadores de futebol das categorias de base dos clubes.

\section{Metodologia}

Desenvolveu-se uma linha metodológica que se enquadrou em uma pesquisa de base qualitativa. Destaque-se que a pesquisa de base qualitativa pode, de forma mais adequada, responder a assuntos que são propostos, assim como permite interpretar melhor as respostas dos entrevistados, uma vez que esse tipo de pesquisa trata essencialmente "com o universo de significados, motivos, aspirações, crenças, valores e atitudes, o que corresponde a um espaço mais profundo das relações" (MINAYO, 1994, p. 21-22). Em relação ao instrumento de pesquisa, foram utilizadas entrevistas semiestruturadas e, para análise dos dados obtidos, utilizou-se a técnica do Discurso do Sujeito Coletivo (DSC), desenvolvida por Lefèvre e Lefèvre. Ela organiza e tabula dados qualitativos de natureza verbal. O material verbal extraído de cada um dos depoimentos é analisado e, ao final é construído um discurso. Para a elaboração 
do DSC, é necessária a realização de quatro operações: as Ideias Centrais (ICs), as ExpressõesChaves (ECs), as Ancoragens (ACs) e o Discurso do Sujeito Coletivo (DSC) propriamente dito (LEFÈVRE; LEFÈVRE, 2003).

Lefèvre e Lefèvre afirmam que a organização dos discursos acontece mediante a junção de fragmentos, isto é, das expressões-chaves das respostas dos entrevistados. Tais fragmentos constituem o fundamento de uma determinada ideia central em torno da qual é elaborado um discurso. A ideia central é abstraída de um conjunto de expressões-chaves, que são identificadas por meio de diferentes respostas a determinada pergunta indicada pelo roteiro de entrevista. Os diferentes conjuntos de expressões-chaves que correspondem a uma ideia central foram associados, resultando na identificação de diferentes discursos sínteses. Para Lefèvre, Lefèvre e Teixeira “... em síntese, o DSC é como se o discurso de todos fosse o discurso de um” (2000, p. 83). Neste sentido, a reunião de tais discursos corresponde à revelação do alicerce coletivo da fala de cada um dos participantes da pesquisa, isto é, no Discurso do Sujeito Coletivo (DSC) que representa a essência do conteúdo discursivo dos entrevistados.

\section{Resultados e discussões}

A partir das entrevistas realizadas com os jogadores e seus pais, com auxilio da técnica do DSC, reuniram-se as respostas em quatro categorias temáticas, as quais são apresentadas a seguir por meio de quadros que contêm as ideias centrais extraídas das expressões-chaves que compõem os discursos dos participantes.

Vale ressaltar que foram 7 participantes da pesquisa, sendo: 2 jogadores residentes no alojamento do clube, 2 jogadores não residentes (estes últimos moram com os pais na cidade do Porto), assim como os pais destes jovens, sendo 1 pai de jogador residente no alojamento do clube e 2 pais de jogadores não residentes. Para tanto, as seguintes nomenclaturas foram utilizadas para melhor identificação dos participantes, a saber: JR1 - jogador residente 1, JR2 - jogador residente 2, JNR1 - jogador não residente 1, JNR2 - jogador não residente 2, PJR1 pai de jogador residente 1 , PJNR1 - pai de jogador não residente 1 , PJNR2 - pai de jogador não residente 2 .

A primeira categoria denomina-se "Dificuldades e implicações da conciliação entre os treinos e as obrigações escolares", composta por 5 (cinco) IC dos jogadores e três dos pais, conforme o Quadro I. 
Quadro 1- Dificuldades e implicações da conciliação entre os treinos e as obrigações escolares

\begin{tabular}{|c|c|c|}
\hline Participantes & Jogadores & Pais \\
\hline Ideias-centrais & $\begin{array}{l}\text { A. Ser muito mais responsável } \\
\text { B. Tenho que ter tudo sistematizado } \\
\text { C. Tenho que me reservar } \\
\text { D. É complicado } \\
\text { E. Faltamos muito nas aulas }\end{array}$ & $\begin{array}{l}\text { A. Prejuízos por conta do tempo } \\
\text { B. É um esforço muito grande } \\
\text { C. Não tem implicação nenhuma }\end{array}$ \\
\hline
\end{tabular}

Fonte: Elaboração própria (2021).

De acordo com os resultados reunidos nesta categoria, notam-se as diversas dificuldades e implicações da conciliação entre os treinos e as obrigações escolares, uma vez que tanto os jogadores como os pais revelaram que há prejuízos na escolarização. Estes se dão por conta do tempo que é despendido nos treinos e, principalmente, devido à participação em jogos fora da cidade, o que ocasiona muitas faltas na escola, como é evidenciado nos DSC a seguir:

[...] muitas vezes faltamos segunda, terça e quarta quando os jogos são fora, depois temos a seleção, perdemos muitos dias e quando voltamos estamos mesmo à toa da matéria, às vezes não conseguimos acompanhar, mas temos que estudar e tentar fazer o melhor. No passado não tive condições, tive que faltar umas aulas e tive até uns três meses porque 'tava' fora do país a representar a seleção nacional e, quando voltei, encontrei dificuldades na escola; mas, foi preciso trabalhar e [...] consegui conciliar [...] tive até que estudar em casa; tentava acompanhar para não tirar negativas na escola para poder no ano passar e transitar de classes (DSC-JR1; JR2).

De acordo com Damo (2005), para se profissionalizar no futebol, o indivíduo despende aproximadamente de 5.000 horas nos treinamentos, acarretando implicações a outras áreas da sua vida, com destaque para a escolarização. Entretanto, é evidente que essa dedicação não garante que esses jovens consigam ingressar na categoria profissional do futebol, uma vez que na transição para a profissionalização há diversas possibilidades de ocorrerem injustiças que resultarão em desligamentos, empréstimos ou negociações desses jogadores para outros clubes (BRUNORO; AFIF, 1997).

Neste sentido, no DSC dos pais, ressalta-se também a questão do tempo como uma das principais dificuldades percebidas por eles em relação aos filhos sobre conciliar a formação esportiva e a escolar.

[...] o tempo é muito mais escasso comparativamente se estivesse só dedicado aos estudos. Eu penso que em parte poderá haver algum prejuízo porque [...] eles têm treinos diários, tem horário muito preenchido, [...] e eu acredito que a disposição para ir às aulas de tarde [...] não será a melhor, [...], pois, têm duas horas de treino; há 
sempre algum cansaço e se calhar não há muita paciência para estar nas aulas (DSCPJNR1; PJR1).

Nessa trajetória iniciada nas categorias de base até a profissionalização, os jovens vivenciam momentos de muitos esforços e sacrifícios, uma vez que o futebol, em muitos casos, é encarado como um ideal de vida, "especialmente se o jovem candidato a atleta demonstra indícios de um talento promissor. Porém, mesmo essa soma de talento e dedicação coletiva não garante que tudo correrá às mil maravilhas" (COUTO, 2014, p. 39).

As faltas e o tempo reduzido para os estudos passam a ser obstáculos para a permanência desses jovens na formação escolar que, de acordo com Balzano, "após ingressarem em uma equipe de futebol, visando uma oportunidade de crescimento, muitas vezes acabam abandonando os estudos e não chegam a concluir o ensino médio" (2008, p. 7).

A categoria denominada “Apoio/acompanhamento do desempenho escolar", conforme exposto no Quadro II, reúne as ideias-centrais encontradas a partir dos relatos de jogadores e de pais sobre como se dá o apoio/acompanhamento do desempenho escolar. Nota-se, a partir das IC, que o acompanhamento é realizado pela parte pedagógica do clube, pela própria escola e também pelos pais.

Quadro 2 - Categoria temática: Apoio/acompanhamento do desempenho escolar

\begin{tabular}{|c|c|c|}
\hline Participantes & Jogadores & Pais \\
\hline Ideias-centrais & $\begin{array}{l}\text { A. Tiramos um tempo para estudar } \\
\text { B. Tem que ser nós mesmos } \\
\text { C. Professores ajudam via internet } \\
\text { D. Nas viagens longas sempre tem } \\
\text { acompanhamento } \\
\text { E. Temos horário especial } \\
\text { F. Colegas ajudam } \\
\text { G. Sim, nos lembram que temos que estudar } \\
\text { H. Bom acompanhamento } \\
\text { I. Temos testes por período } \\
\text { J. Comunicação escola-departamento }\end{array}$ & $\begin{array}{l}\text { A. Sim, mas temos noção que é difícil } \\
\text { B. Sim, temos que acompanhar para que } \\
\text { estude } \\
\text { C. Fica a cargo deles, mas acompanhamos }\end{array}$ \\
\hline
\end{tabular}

Fonte: Elaboração própria (2021).

A escola oferta horários especiais e promove a comunicação com o departamento pedagógico do clube. Carvalho (2002) discorre sobre a necessidade de haver aproximação e colaboração entre a escola e o clube, pois os horários das atividades esportivas ocorrem simultaneamente com os escolares e é preciso criar estratégias visando a evitar o abandono escolar. Além disso, os colegas de classe e professores exercem importante papel no auxílio aos 
jovens jogadores para a conciliação dos treinos e desempenho escolar, principalmente quando necessitam ausentar-se para as competições. Conforme exposto no DSC a seguir:

[...] fui para uma turma especial e somos em quatro jogadores do Porto e temos horários especiais de acordo com os treinos que temos. E todas as semanas nós faltamos aulas e sempre aos fins de semana nós recebemos um e-mail, ou dos professores, ou dos colegas de turma que nos mandam o que perdemos nas aulas em que faltamos. São turmas normais; só que a nossa escola faz horários especiais por causa dos alunos do FCPorto. A escola se adapta os horários, porque é uma escola com acordo com o FCPorto (DSC - JNR1; JNR2; JR1).

Os clubes ofertam assistência de diferentes maneiras, por meio do apoio, acompanhamento pedagógico e aconselhamentos sobre a importância de se manterem estudando. Além disso, nas viagens realizadas pelos jogadores, é prática do clube enviar alguém para monitorar, auxiliar e incentivar os jogadores nos estudos. Dado que se diverge do que apontam Brunoro e Afif (1997), uma vez que afirmam que muitos clubes não se procupam em proporcionar aos jogadores a vivência de outros elementos importantes para a vida.

[...] quando é muito longo, temos sempre alguém a nos acompanhar e, lá na seleção, também é a mesma coisa (DSC - JR1).

Eu tenho um exemplo que, no início deste ano, em janeiro, eu fui duas semanas para Malásia e o Dr. Nelson do Porto foi conosco e todos os dias, nós tivemos uma hora em que nós tivemos que trazer os livros de casa e tivemos lá a estudar (DSC - JNR1).

O interesse pelo bom andamento escolar dos jogadores também é regulado pelos pais, conforme pode-se notar no discurso a seguir:

Sim, [...] eu sou a pessoa primeira, [...] quer eu, quer a mãe, a incentivá-lo para que estude, [...]; tudo pode ser efêmero e tem que haver [...], uma estrutura [...] capaz de fazer perceber as várias etapas da vida, mesmo no desporto, [...], não pode viver [...] numa expectativa que não seja real, [...], há muitas variáveis que podem condicionar que se chegue mais longe e, portanto, o estudo aqui é uma peça importante. Ele sabe que nós lhe damos o apoio que podemos, e a mãe e eu incentivamos sempre para estudar (DSC - PJNR1; PJNR2).

$\mathrm{O}$ apoio aos jogadores também se dá por meio da figura do treinador, que realiza cobranças e aconselhamentos, principalmente sobre as incertezas na carreira futebolística.

Claro que nosso treinador quer que nós nos empenhemos ao máximo nos treinos, mas também sabe [...] que a escola é bastante importante [...] e também ajuda-nos a lembrar que temos que estudar; o futebol não é assim uma certeza. [...] Então, eles apoiam-nos também, os treinadores, às vezes, perguntam se está tudo bem, quer no campo, ou na escola; também [se] preocupam sempre e, às vezes, até falam do passado e dizem que é muito importante pra nós todos termos um bom estudo para depois (DSC - JNR1; JNR2). 
Em relação à influência do treinador, Araújo (1994) destaca que este profissional, além de atuar como um formador de conhecimentos específicos do esporte age também como um elemento de transmissão de valores sociais, culturais, educativos e comportamentais.

De acordo com Picanço (2012), a escolarização dos jogadores deve ser uma preocupação de todos os agentes responsáveis pela educação; portanto, pais, treinadores e o clube em geral devem atuar como grandes incentivadores para que esses jovens não se distanciem do processo educativo da sala de aula. Para isso, devem estabelecer comunicações e contato regular entre si (pais, escola e clube), para que o desenvolvimento do educando ocorra de maneira saudável.

De acordo com o Quadro III, os jogadores demonstram em seus discursos que a pressão, cobranças e penalidades por que passam provêm da parte pedagógica dos clubes e da própria família.

Quadro 3 - Categoria temática: pressão, cobranças e penalidades sofridas em relação ao rendimento escolar

\begin{tabular}{|l|l|l|}
\hline \multicolumn{1}{|c|}{ Participantes } & \multicolumn{1}{|c|}{ Jogadores } & \multicolumn{1}{|c|}{ Pais } \\
\hline \multirow{4}{*}{ Ideias-centrais } & A. Pressão pela parte pedagógica e da família & A. Sim, eu cobro \\
& $\begin{array}{l}\text { B. Pressão pela parte pedagógica } \\
\text { C. Desempenho deve ser bom no futebol e na }\end{array}$ & $\begin{array}{l}\text { B. Eu cobro } \\
\text { C. Minha esposa acompanha, eu cobro }\end{array}$ \\
& $\begin{array}{l}\text { D. Somos obrigados a estudar } \\
\text { E. Costuma falar quando há más notas }\end{array}$ & \\
& $\begin{array}{l}\text { F. Nas categorias mais baixas dão castigo } \\
\text { G. Nas categorias mais altas aconselha, mas }\end{array}$ & \\
& não pune & \\
\hline
\end{tabular}

Fonte: Elaboração própria (2021).

A pressão exercida pelos clubes materializa-se na obrigatoriedade dos estudos e na cobrança da "jogada perfeita", ou seja, conciliam a formação esportiva com a escolar. Estarem bem nas duas coisas é indispensável para o clube e para a família. Entretanto, percebe-se que a atuação de todos os profissionais, no que diz respeito a quaisquer ações de caráter punitivo e de cobrança, deve estar devidamente coerente e fundamentada, pois, conforme Coelho (1990), não existe um processo formativo dos que praticam atividades esportivas sem que haja uma adequada formação daqueles que estão responsáveis pela organização, direção e acompanhamento de tais ações. 
Nos discursos, a seguir, tanto os pais quanto os jogadores entrevistados evidenciam essas cobranças.

[...] sentimos pressão não só da parte pedagógica, mas, no meu caso, em casa com a minha família, porque os meus pais são bastante rigorosos com a escola; [...] se eu não tiver boas notas também eu não posso jogar a bola; [...] mas, aqui também, quando veem que as nossas médias, as nossas notas começam a baixar, então [...] chamamnos, $[\ldots]$ e o que que está a passar contigo? Por que é que estás a baixar as notas? E tentam nos ajudar e a perceber o porquê desta caída [...] (DSC- JNR1).

Sempre, eu, em casa, tenho sempre uma fiscal, um árbitro, que é a minha esposa, que tem o ensino superior completo e que é docente também, e nós [...] distribuímos algumas tarefas e a dela é de fazer o acompanhamento diário e a minha é mais de cobrar. [...] O meu filho [...] joga futebol desde os 5 anos; ele sempre teve, tanto da minha parte e da mãe, um feedback que ele jogaria futebol desde que continuasse a estudar e passar de ano e, de preferência, com boas notas (DSC - PJNR1).

Nas categorias de base, abaixo da Sub 17, chegam a lançar mão de punições e castigos para aqueles que apresentam baixo rendimento escolar. No entanto, observa-se que nas categorias mais altas, a exemplo a sub 19, a atmosfera de cobrança é apaziguada; as punições e castigos não se fazem tão presentes; o interesse pelo bom andamento escolar dos jogadores, embora ocorra, parece ficar em segundo plano, conforme o discurso a seguir:

\footnotetext{
Quando chegamos já no sub 19 e a competição é mais a sério, os treinadores [...] apoiam-nos; dizem-nos a importância da escola [...], aconselham-nos, mas não nos dão punição [...] se o treinador precisar de um jogador, não vai dar um castigo só porque não teve um bom rendimento escolar, mas, tipo, dá conselho que tem que ir pra escola (DSC - JR2).
}

A última categoria temática apresenta as IC que dizem respeito aos benefícios que jogadores e pais consideram que ocorrem devido ao bom desempenho escolar. Nota-se que boa parte dos jogadores refere-se aos benefícios gerados pelos fatores cognitivos e táticos, como o aumento da concentração e da "rapidez mental", que poderia ser traduzida como a capacidade de tomada de decisão, habilidade indispensável para qualquer futebolista.

Nas IC dos pais, os beneficios denotam a preocupação direta com os aspectos acadêmicos, inclusive em relação à continuidade dos estudos por esses jovens, com o ingresso no ensino superior, todavia, reconhecem a importância do trabalho desenvolvido pelo departamento pedagógico do FCPorto. Esta apreensão remete-se ao que Balzano (2008) e Damo (2005) já evidenciaram: a diminuição da permanência escolar desses jovens jogadores e, por vezes, o abandono da formação escolar prejudicando a formação integral deles. 
Quadro 4 - Categoria temática: os benefícios e perspectivas quanto ao desempenho escolar

\begin{tabular}{|c|c|c|}
\hline Participantes & Jogadores & Pais \\
\hline Ideias-centrais & $\begin{array}{l}\text { A. Sim, concentração na escola reflete em } \\
\text { concentração no futebol } \\
\text { B. Sim, tornamo-nos mais rápidos } \\
\text { mentalmente } \\
\text { C. Sim, percebe melhor as coisas } \\
\text { D. Quanto mais conhecimento, melhor será } \\
\text { a adaptação } \\
\text { E. Sim, a Federação nos ajuda } \\
\text { F. Sim, a seleção também pode ajudar }\end{array}$ & $\begin{array}{l}\text { A. Acho importantíssimo, mas os clubes } \\
\text { visam mais formar para o futebol } \\
\text { B. Deveria haver mais exigência } \\
\text { C. Sim, deveria ser obrigatório } \\
\text { D. Não, fazem pouca coisa } \\
\text { E. Tem o estatuto de atleta de alta } \\
\text { competição } \\
\text { F. Tem acesso facilitado ao ensino superior } \\
\text { G. Tem auxiliares de educação }\end{array}$ \\
\hline
\end{tabular}

Fonte: Elaboração própria (2021).

Di Pierro (2015) ressalta que o jogador deve ser inteligente, pensar e resolver problemas. Portanto, permanecer na escola é importante para que desenvolva ainda mais suas capacidades cognitivas e tornar-se um ser com visão mais ampla, possibilitando melhor desempenho no campo.

Tornamo-nos mais rápidos mentalmente e ajuda-nos a solucionar uma situação em que tem que ser muito rápido a decidir. A parte mais importante do futebol é quase a cabeça e [...] nós temos que trabalhar o nosso cérebro e reforçá-lo [...], com coisas da escola para que, depois, no futebol, aconteçam, [...] Às vezes, não temos tempo pra pensar e tem que ser o nosso raciocínio a dar a opção mais certa, num curto período de tempo, e acho que ajuda imenso. Um bom jogador para ser bom tem que pensar mais depressa, ser mais criativo; por isso, à partida, o fato de ser bom aluno ajuda certamente a ser mais inteligente dentro do campo (DSC - JNR1; JNR2; JR1).

Rego (2003) observa que o espaço escolar propicia o desenvolvimento global dos indivíduos por meio de ações determinadas e executadas no contexto da sala de aula e fora dela.

Para tanto, os pais consideram importantíssimo que haja exigência por parte dos clubes quanto à formação escolar dos jogadores. No entanto, sabe-se que a preocupação maior é com os valores gerados pelo futebol.

Sim, acho que é importantíssimo, só que, muitas das vezes, o produto tem que ser imediato, e, portanto, tem que ser o futebolista, tem que ser o atleta e acho que eles se esquecem um bocado disso [...] Eu acho que é importante eles apostarem na formação e na formação [...] escolar, é aquilo que o Porto tem feito. Agora, nós também temos noção que os grandes clubes querem é formar jogadores [...], mas [...], cada vez mais, muitos jogadores conseguem ter um bom nível escolar também, porque [...] há essa conciliação muitas vezes do jogador inteligente em nível escolar ser inteligente no campo; agora, nós sabemos que a prioridade é sempre formar jogadores de futebol para os clubes, porque são os jogadores que lhes dão dinheiro [...], e o futebol também é dinheiro [...] e a escola se calhar fica em segundo plano (DSC - PJNR1; PJR1). 
É sabido que as categorias de base dos clubes de futebol têm como principal interesse a formação de jovens jogadores que possam representar no futuro a equipe profissional e, consequentemente, garantir lucros financeiros com a negociação desses jogadores no mercado futebolístico. Entretanto, é fundamental aos clubes assumir a responsabilidade e o compromisso de colaborar com o processo educativo da juventude inserida no contexto esportivo criando condições para que os jogadores possam desenvolver o percurso da escolaridade básica. De fato, conciliar os espaços de tempo da formação esportiva com os da formação escolar configura uma emergência para o esporte.

\section{Considerações finais}

A realização desse estudo tem uma latente preocupação com a juventude desportiva que encontra muitas dificuldades para conciliar a formação esportiva com a formação escolar. Apesar do cenário futebolístico retratado, discutido e analisado neste artigo, esta problemática também se apresenta em outros esportes, provavelmente, dependendo da característica da modalidade, dos períodos dedicados aos treinos e competições, do tempo gasto no percurso casa-escola-clube-casa e esta conjuntura seja mais ou menos flexível, ou não.

De acordo com a análise realizada, percebe-se que pais e jogadores reconhecem as muitas dificuldades para conciliar as duas formações. Os participantes da pesquisa também revelaram que o Futebol Clube do Porto e as escolas, na figura dos diretores, professores e colegas de classe, conveniadas à referida agremiação oferecem total assistência, acompanhamento pedagógico e aconselhamentos, evidenciando a importância da escolaridade. Vale lembrar que o referido clube exerce cobrança por meio do monitoramento do desempenho escolar de cada jogador e, quando necessário, pune aqueles com baixo rendimento na escola.

Os jogadores relataram, também, que o treinador sempre está atento às questões escolares e que procura aconselhá-los a valorizar a trajetória acadêmica. Ele alerta acerca das possibilidades de êxito ou insucesso que permeiam o ambiente futebolístico. Em relação aos benefícios desenvolvidos no espaço escolar e que se transferem para o esportivo, os jogadores asseguram que a concentração, o raciocínio rápido e a tomada de decisão são aspectos importantes nos treinos e jogos.

Retomando as hipóteses apresentadas, considerou-se que nenhuma delas se confirmou, pois os jogadores expuseram que, apesar das dificuldades encontradas, é muito importante conciliar a formação esportiva e a escolar. Demonstraram bom discernimento sobre a possibilidade de ocorrer fracasso ou sucesso na trajetória futebolística e a perspectiva de 
realização em outras carreiras. Já os pais valorizam a formação escolar e se mostram presentes e participativos apoiando, acompanhando e cobrando o desempenho dos filhos na escola, perspectivando a continuidade dos estudos no ensino superior.

\section{Referências}

BALZANO, Otávio Nogueira. Projeto esporte social: uma possibilidade de inclusão dos alunos negros, atletas e oriundos de classes populares na escola privada, através do futebol. Dissertação de Mestrado. Centro Universitário La Salle - UNILASALLE. Porto Alegre, 2008.

BRUNORO, José Carlos; AFIF, Antônio. Futebol 100\% profissional. São Paulo: Gente, 1997.

CARVALHO, José Maria. Contributo para a formação profissional de jogadores de futebol: estudo em clubes da Associação de Futebol do Porto da primeira e segunda Ligas de Futebol Profissional. Porto: Dissertação de mestrado apresentada a Faculdade de Desporto da Universidade do Porto, 2002.

COELHO, Olímpio. O Espírito Desportivo e a Formação do Praticante. Revista Horizonte, v. VI, n. 36, p. 187-190, mar.-abr. 1990.

COUTO, Hergos Ritor Froes de. Esporte do oprimido: utopia e desencanto na formação do atleta de futebol. Brasília: Liber livro, 2014.

DAMO, Arlei Sander. Do dom a profissão: uma etnografia do futebol de espetáculo a partir da formação de jogadores no Brasil e na França. 2005. 434f. Tese (Doutorado em Antropologia Social) - Universidade Federal do Rio Grande do Sul, Porto Alegre, 2005.

DI PIERRO, Carla. Diálogos sobre Psicologia do Esporte: Psicologia do Esporte, práticas integrativas e complementares. Do que estamos falando? In: CICLO ESTADUAL DE DEBATES DO CONSELHO REGIONAL DE PSICOLOGIA, 2015. São Paulo: CRP-SP, 2015. Mesa-redonda. Disponível em: http://www.crpsp.org.br/portal/comunicacao/2015_04_27PSIESPORTE/2015_04_27-PSI-ESPORTE.html. Acesso em 27 de abril de 2015.

FERREIRA, Aurélio Buarque de Holanda. Novo dicionário da Língua Portuguesa. 2. ed., 36 imp. Rio de Janeiro: Nova Fronteira, 1986.

LEFÈVRE, Fernando; LEFÈVRE, Ana Maria Cavalcanti; TEIXEIRA, Jorge Juarez Vieira. $O$ discurso do sujeito coletivo: uma nova abordagem metodológica em pesquisa qualitativa. Caxias do Sul: EDUCS, 2000.

LEFÈVRE, Fernando. Discurso do sujeito coletivo: um novo enfoque em pesquisa qualitativa. Caxias do Sul: EDUCS, 2003.

LIMA, Teotónio. A Formação Desportiva dos Jovens. Revista Horizonte, v. V, n. 25, p. 21-26, maio-jun. 1988. 
MACEDO, Ronaldo Contó de. Para além das quatro linhas - as relações entre o futebol e o cotidiano escolar na construção da cidadania. Dissertação de mestrado. Programa de PósGraduação em Educação da Universidade de Sorocaba, 2006.

MARQUES, Mauricio Pimenta; SAMULSKI, Dietmar Martin. Análise da carreira esportiva de jovens atletas de futebol na transição da fase amadora para a fase profissional: escolaridade, iniciação, contexto sócio-familiar e planejamento da carreira. Revista Brasileira de Educação Física e Esporte, São Paulo, v. 23, n. 2, p.103-19, abr./jun. 2009.

MINAYO, Maria Cecília de Souza. (Org.). Pesquisa Social: teoria, método e criatividade. Petrópolis, RJ: Vozes, 1994.

PACHECO, Rui. O ensino do futebol de 7: um jogo de iniciação ao futebol de 11. Porto: Grafiasa, 2001.

PICANÇO, Ana Luísa Bibe. A relação entre escola e família - as suas implicações no processo de ensinoaprendizagem. Dissertação de mestrado - Escola Superior de Educação João de Deus. Mestrado em Ciências da Educação - Supervisão Pedagógica, Lisboa, 2012.

REGO, Teresa Cristina. Memórias de escola: cultura escolar e constituição de singularidades. Petrópolis, RJ: Vozes, 2003.

SEVERINO, Antônio Joaquim. A busca do sentido da formação humana: tarefa da Filosofia da Educação. Educação e Pesquisa, v. 32, n.3, p. 619-634, set./dez. 2006. 